\section{Review Article}

Korean J Transplant 2021;35:137-142 https://doi.org/10.4285/kjt.21.0022
Received September 10, 2021

Revised September 24, 2021

Accepted September 24, 2021

Corresponding author: Curie Ahn Division of Nephrology, National Medical Center, 245 Eulji-ro, Jung-gu, Seoul 04564 , Korea

Tel: +82-2-2276-2143

Fax: +82-2-6455-2149

E-mail: curie@snu.ac.kr

(c) The Korean Society for Transplantation This is an Open Access article distributed under the terms of the Creative Commons Attribution Non-Commercial License (http://creativecommons.org/licenses/ by-nc/4.0/) which permits unrestricted non-commercial use, distribution, and reproduction in any medium, provided the original work is properly cited.

\section{$\mathrm{KJT}$ \\ KOREAN JOURNAL OF TRANSPLANTATION}

pISSN 2671-8790

eISSN 2671-8804

\title{
Improving self-sufficiency in organ transplantation in Korea
}

\author{
Curie Ahn ${ }^{1,2}$, Samuel Lee ${ }^{3}$, Yeong Hoon Kim ${ }^{4}$, Jieun $\mathrm{Oh}^{5}$, Ik Jin Yun ${ }^{6}$, \\ Hyung Joon $\mathrm{Ahn}^{7}$, Soo Hyun Seo ${ }^{2}$, Jong Cheol Jeong ${ }^{8}$, Myung Soo Kim', \\ Jongwon $\mathrm{Ha}^{10}$, Soon II Kim ${ }^{9}$, In Sung Moon ${ }^{11}$, Won Hyun $\mathrm{Cho}^{12}$ \\ ${ }^{1}$ Division of Nephrology, National Medical Center, Seoul, Korea \\ ${ }^{2}$ Vitallink, Seoul, Korea \\ ${ }^{3}$ Department of Surgery, KangNam Sacred Heart Hospital, Hallym University College of Medicine, Seoul, Korea \\ ${ }^{4}$ Division of Nephrology, Inje University Busan Paik Hospital, Busan, Korea \\ ${ }^{5}$ Department of Internal Medicine, Hallym University Kangnam Sacred Heart Hospital, Seoul, Korea \\ ${ }^{6}$ Department of Surgery, Konkuk University Medical Center, Seoul, Korea \\ ${ }^{7}$ Department of Surgery, Kyung Hee University Medical Center, Seoul, Korea \\ ${ }^{8}$ Division of Nephrology, Seoul National University Bundang Hospital, Seongnam, Korea \\ ${ }^{9}$ Department of Surgery, Yonsei University College of Medicine, Seoul, Korea \\ ${ }^{10}$ Department of Surgery, Transplantation Research Institute, Seoul National University College of Medicine, \\ Seoul, Korea \\ ${ }^{11}$ Korea Organ Donation Agency, Seoul, Korea \\ ${ }^{12}$ Department of Surgery, Keimyung University School of Medicine, Daegu, Korea
}

After attaining a qualified medical capacity in organ transplantation, Korea has been struggling to increase the number of deceased organ transplants to reach self-sufficiency. As one of these efforts, Korea revised the organ transplantation law in 2010 by adding three articles the mandatory reporting based on the recommendation of the 3rd Global Consultation on Organ Transplantation of Madrid in 2010. Along with the new constitution, considerable efforts have been initiated to upgrade the deceased organ transplantation system while maintaining the virtues of fairness, justice, and transparency. The Korean Society of Transplantation played a critical role in revising the law as well as in establishing organizations such as the Korean Organ Donation Agency (KODA; 2009), the Vitallink (2009), and the Korean Organ Transplantation Registry (KOTRY; 2010). By the activities of these professional organizations, Korea could implement fundamental programs such as mandatory reporting and could develop various education programs for organ donation for students and the general population. As a result, the number of deceased donors increased from 1.08 p.m.p. (2000) to 9.23 p.m.p.(2020). Further efforts are needed to increase the number of organ donor cardholders and family consent rates by well-designed, target-specific education programs to overcome traditional negative cultural barriers toward organ donation. The community atmosphere of honoring and thanking donors and their families should be nurtured by national and regional activities of life-sharing weeks linked with organ donor memorial parks.

Keywords: Korean organ transplantation; Deceased organ transplantation; Self-sufficiency; Organ donation 


\section{HIGHLIGHTS}

- Legislation and establishment of a national transplantation organization, Korean Network for Organ Sharing (KONOS).

- The National Independent Organ Procurement Organization, Korean Organ Donation Agency (KODA).

- Involvement of the intensive care unit and emergency room for early notification of potential brain death donors.

- Reducing family refusal through "my family should know about my wish" campaign.

- High-school and medical school education program for organ donation with Vitallink.

- Establishing a National Transplantation Database Korean Organ Transplantation Registry (KOTRY) for Objective Monitoring.

\section{INTRODUCTION}

The number of organ transplantations has increased continuously in Korea, and more than 4,000 transplantations were performed in 2020 [1]. The organ transplantation program started in 1969 with a living donor kidney transplantation, which was followed by the first deceased donor kidney transplantation in 1979. Most of the transplanted patients have enjoyed not only a good quality of life but also the economic benefit of organ transplantation since the average cost for a living donor kidney transplantation at 3rd year after transplantation is about one-quarter of that of colon cancer [2]. Because of the previously mentioned and many other benefits for organ transplantation, leading hospitals had established high-volume organ transplantation centers and had developed programs for organ procurement from deceased donors in the department or the centers. We call this type of organ procurement program a hospital-based organ procurement organization (HOPO).

However, waiting lists and waiting times grow longer and longer every year, and death cases while waiting reached up to 5.8 patients per day in 2019 , even with the competitive establishment of deceased organ transplantation programs in many hospitals [3]. This situation has driven devastated end-stage organ failure patients into seeking illegal ways for organ transplantation. Initially, illegal organ transplantation started with personal interactions between donors and recipients. It then changed into underground organizations or crime syndicate-mediated activities. Currently, these patients seek opportunities for overseas transplantation through web-based black markets. In 2008, the Transplantation Society and World Health Organization (WHO) proclaimed the Declaration of Istanbul (DOI) [4]. The $\mathrm{DOI}$ requests each government for its national responsibility and global cooperation in the protection from organ selling, in terminating organ trading, and completing national self-sufficiency. In 2010, the 3rd global consultation on organ transplantation was held in Madrid [5], in which three categories of national responsibilities for self-sufficiency were defined. These were increasing organ availability; ensuring fairness, justice, and transparency; and preventing the need for transplantation. Two action plans were presented to accomplish these three goals. These were to establish a legislative and regulatory framework and establish a national transplantation organization (NTO).

\section{LEGISLATION AND ESTABLISHMENT OF NTO, KOREAN NETWORK FOR ORGAN SHARING}

Meanwhile, Korea adopted the organ transplantation law in 1999 and established a national organ transplantation organization called the Korean Network for Organ Sharing (KONOS; 2000, https://www.konos.go.kr). KONOS has been responsible for managing the waiting list, allocating organs procured from deceased donors, addressing coordination and policy implementation, and playing a major role in the regulation and evaluation of organ transplantation activities. When KONOS implemented highly strict regulatory surveillance for every transplantation process, the number of deceased organ donors decreased sharply. This event resulted in a reciprocal increase in cases of overseas organ transplantation, and the main destination country for unethical transplantation activity was China [6], in which we carefully reviewed the WHO requirements. We found that we need to develop an efficient and principled organ procurement organization (OPO) based on the transplantation database. In this context, we revised the organ transplantation law in 2010 to insert additional articles on the establishment of OPO, an adaptation of mandatory reporting of potential brain-dead donors, and the establishment of a national transplantation registry. 


\section{THE NATIONAL INDEPENDENT ORGAN PROCUREMENT ORGANIZATION, KODA}

The most immediate task was to establish an OPO. We concluded that we were to build a national, independent OPO (IOPO) because in comparison to HOPO, IOPO can activate the organ procurement process in non-HOPO hospitals, IOPO can maximize the use of donated organs, the standardized process can be adapted easily, and it can cooperate with tissue and eye donation using a national network. The government agency, the Korean Organ Donation Agency (KODA; https://www.koda1458.kr), was established as an independent, national OPO in 2009.

\section{INVOLVEMENT OF THE INTENSIVE CARE UNIT AND EMERGENCY ROOM FOR EARLY NOTIFICATION OF POTENTIAL BRAIN DEATH DONORS}

Our next step was to implement mandated reporting of potential deceased donors because the reporting rate was around $15 \%$ in major hospital emergency units and intensive care units (ICUs) [7]. The most common reason for the reluctance to report was that doctors were afraid of facing any risk of conflict with family members because mentioning brain death could be misunderstood as giving up full medical care by the family. Next was a lack of knowledge on organ donation, since only $32 \%$ had received any education about deceased organ donation.

A call center system was launched at KODA to receive reports for 24 hours. The donation improvement program (DIP) was initiated using regular hospital attitude evaluations and medical record reviews. Early notification from the emergency room and ICU was the most critical factor in initiating deceased organ donation. To reduce the burden of medical professionals facing family members, a call center system was launched at KODA to receive reports for 24 hours. Education seminars on the value and process of deceased organ donation and deceased donor management in ICUs were provided to improve participation from hospitals. The DIP was also started using regular hospital attitude evaluations and medical record reviews.

By applying the legislation of the organ transplantation law, establishing a NTO, establishing a national independent OPO, and adopting mandatory reporting of potential deceased donors, the number of actual deceased donors increased markedly, with the decreasing number of overseas transplantation cases (Fig. 1) [8].

\section{REDUCING FAMILY REFUSAL THROUGH “MY FAMILY SHOULD KNOW ABOUT MY WISH" CAMPAIGN}

Despite all these efforts to promote deceased organ donation programs, the number (p.m.p) of the actual deceased donors in Korea remained very low [9]. In 2019, Korea ranked 31st among the 37 Organisation for Economic Co-operation and Development (OECD) countries. This suggests that there are cultural barriers, including Confucianism, which prohibits the mutilation of the body and the

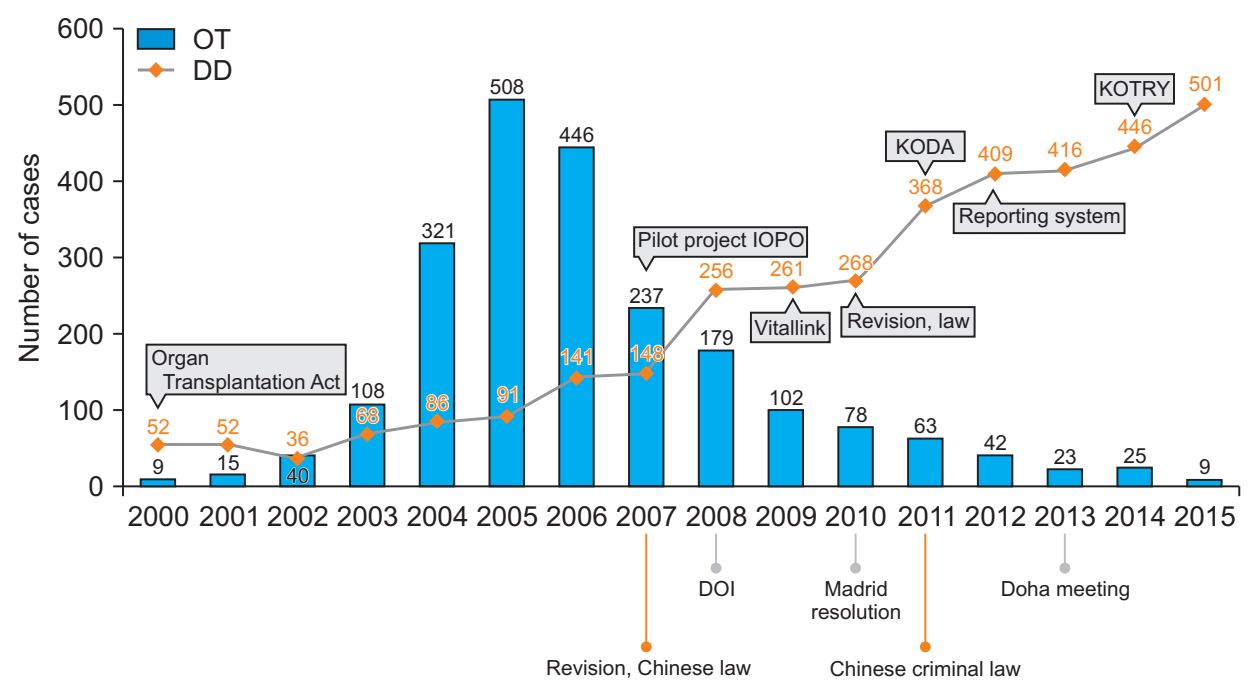

Fig. 1. Number of overseas transplantation (OT) cases and deceased donors (DDs). IOPO, independent organ procurement organization; KODA, Korean Organ Donation Agency; KOTRY, Korean Organ Transplantation Registry; DOI, Declaration of Istanbul. Modified from Ahn HJ, et al. [8]. 


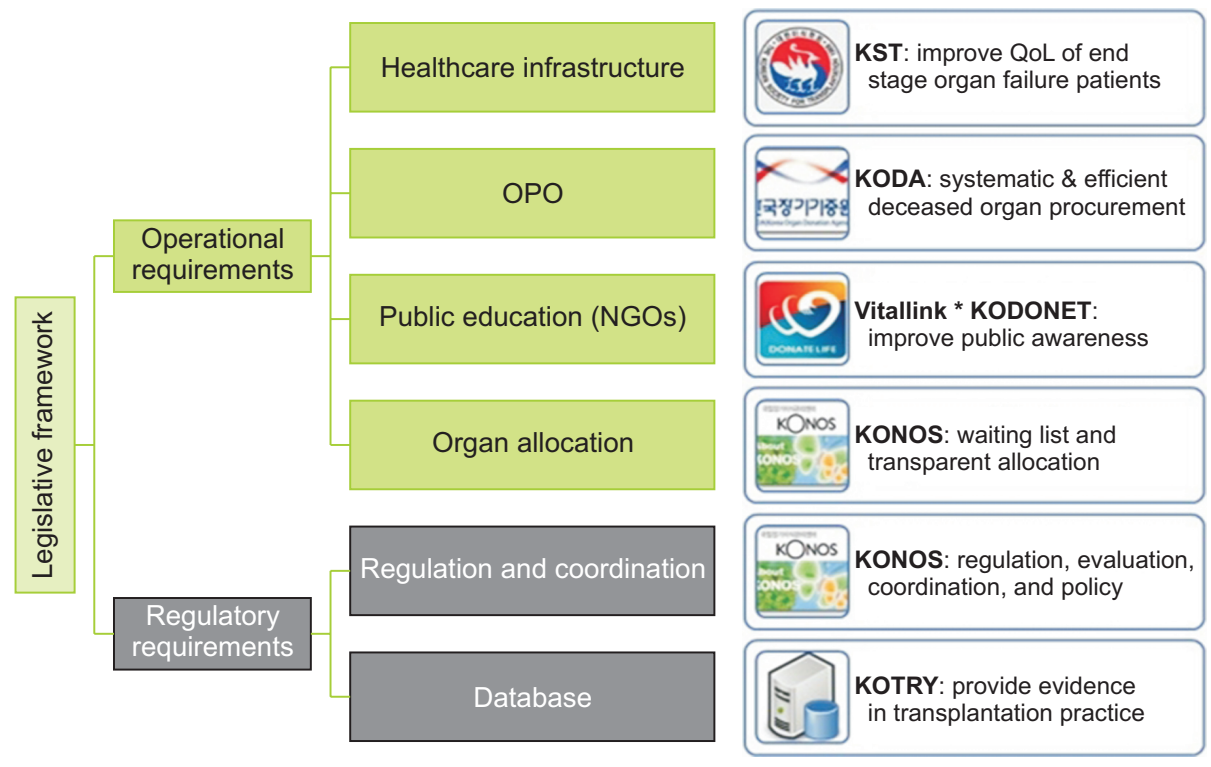

Fig. 2. Structure and function of the Korean organ transplantation organizations. $\mathrm{OPO}$, organ procurement organization; NGO, non-governmental organization; KST, Korean Society of Transplantation, QoL, quality of life; KODA, Korean Organ Donation Agency; KONOS, Korean Network for Organ Sharing; KOTRY, Korean Organ Transplantation Registry. respect of family members in decision-making. We are applying the OPT-in system for the final decision in deceased organ donation because Korea has been a family-oriented society. When we analyzed the main causes of donation failure, family refusal was the most common reason [10]. The KODA annual report also showed a family consent rate of only $33 \%$, which brings a huge drop in the consent rate [11]. Unfortunately, the consent rate is decreasing every year. It is not easy to make a final decision regarding organ donation when a family member is diagnosed with brain death in a hospital. To overcome the family refusal, we started the "My Family Should Know About My Wish" campaign, simplified the family consent process, and processed to respect the donor's right and/or wish by legislating first-person authorization. We decided to promote donation after the circulatory death program. The "My Family Should Know About My Wish" campaign provides communication skills with the family for new and old organ donor card holders, linked to YouTube. First-person authorization for consent is based on the concept that every adult has a legally binding right to decide on deceased organ donation before the death of oneself. The first-person authorization consent law is currently in the process of legislation in Congress. This law will include a guideline for clear documentation using drivers' licenses or health insurance cards and honoring authorization, especially in cases of withdrawal of life-sustaining treatment.

\section{HIGHSCHOOL AND MEDICAL SCHOOL EDUCATION PROGRAM FOR ORGAN DONATION WITH VITALLINK}

In 2017, we experienced a sudden decline in the number of deceased donors. Introduction of "law on withdrawing life-sustaining treatment," a negative media report on post-donation care, and adaptation of the maximum 52hour workweek which reduced workhours of hospital staff and increment of family refusal due to negative social networking service (SNS) contents were the main causes. To improve public awareness, the second week of September was dedicated to the "National Life-Sharing Week (2017)" and the Korean Society of Transplantation (KST) has been performing various activities to promote public awareness through an non-governmental organization (NGO) named Vitallink (http://www.vitallink.or.kr/) and an NGO network called the Korean Organ Donation Network. However, the organ donor registration rate was only $4 \%$ among the adult population [1]. The main reasons for refusing donor card registration by the population attitude survey by Centers for Disease Control and Prevention (CDC) were hesitation to register with vague causes, do not know how to register, ambient opposition, and complicated registration process. The main reasons for unwillingness to register were body damage or mutilation, vague fear of the actual organ procurement process, lack of information, and lack of experience [12].

In Korea, more than 30 NGOs have been promoting deceased organ donation, even using different kinds of donor 
cards; however, its content lacks consistency, and most commonly, the activity is conducted through low-impact one-time campaigns. As a result, more than $90 \%$ of the general population are aware regarding deceased organ donation; however, they do not have enough knowledge to the level of understanding [13]. The level of understanding that may lead to the final decision on deceased organ donation can only be achieved by systematic education, not by publicizing using events. For the next targets of the public awareness education expansion, followed by medical staff and students, high school and middle school students and medical students were selected. On- and off-line-based organ donation teaching aid libraries were constructed using diverse approaches, such as YouTube Vitallink Academy Channel (https://www.youtube.com/ channel/UC7nB_HQ1E-vj4WtqvwiZGKA).

The youth education manual was developed and published for middle- and high-school students by the Vitallink Education Committee. After communicating with the teachers, a school education program was implemented. As a result, we received feedback responses from many students, describing "Life sharing, I want to do it once before I die! I discovered that organ donation could save many people."

Encouraged by the high- and middle-school education results, we developed a pre- and medical school education program. This program was applied for the first-time to the first-grade pre-medical student class of Seoul National University. Before the class, a survey was conducted using a poll developed by "Nextresearch Co.," a company that specializes in public opinion polls. Thirty-six main questionnaires were used to evaluate the knowledge, attitude, and PR effect. The students were then divided into 20 groups of six to eight participants and studied using the provided self-study materials. Every study group was asked to present a poster about one of the three assigned topics of "What is brain death and deceased donor organ transplantation?", "Why is the deceased donor organ transplantation rate low in Korea?", and "How can we promote deceased organ donation?." The best posters from every three topics were selected, and three selected study group leaders prepared pre-recorded presentations for 5-10 minutes. The main lecture lasted for 1.5 hours with an introductory video, best poster presentations, question and answer, and summary. After finishing the class, a post-education survey was conducted using a list of 15 questionnaires. When this education tool was applied to them, we saw a huge improvement in their attitude and knowledge (unpublished material).

\section{ESTABLISHING A NATIONAL TRANSPLANTATION DATABASE KOREAN ORGAN TRANSPLANTATION REGISTRY FOR OBJECTIVE MONITORING}

The last mission of constructing the national transplantation registry is based on its usefulness for understanding the status and trend in transplantation, detecting risk factors that have a negative impact, and promoting research such as biomarker studies and other clinical research. With the help of global leader registries, we established the Korean Organ Transplantation Registry (KOTRY; https://www.kotry.org). Since KONOS wishes to run a simple registry for the government's needs, KOTRY was designed as a cohort, aiming to promote research in transplantation. KOTRY has mounted an on-time visualization program and a biobank that can collect and store samples within 24 hours. KOTRY provided a basis for another transplantation database, the Asian Society Transplantation Registry (ASTREG). The ASTREG consists of three different database platforms, ASTREG-N for national data, ASTREG-H for hospitals, and a platform for linking databases for existing national registries.

\section{CONCLUSION}

In summary, under the basis or WHO requirement, which was provided during the 3rd global consultation on organ transplantation in Madrid 2010, our governmental and hospital structures and organizations were established by adding two fields: public awareness and coordination and policy. Milestones in organ transplantation program in Korea include the legislation of the organ transplantation law (1999, 2010); establishing a NTO (KONOS, 2000); establishing a national, IOPO (KODA, 2010); and legislation and implementation of mandatory reporting law. Declaring "National Life-Sharing Week (2017), spreading the "My Family Should Know About My Wish" campaign, legislating first-person authorization law, and developing education programs for the high-priority target population play a key role in promoting public awareness. The National Transplantation Registry (KOTRY 2014, KONOS database) provides the basis for understanding trends in transplantation practice (Fig. 2). The first donation after circulatory death (DCD) was performed in 1997 [14], but there is still room for development in this program. Only one case of DCD was reported in 2020.

Further efforts are needed to increase the number of organ donor cardholders and family consent by efficient and 
meaningful programs such as well-designed, target-specific education programs and structures such as memorial parks for building a nationwide culture to honor and offer thanksgiving to the donors and their families in Korea.

\section{ACKNOWLEDGMENTS}

\section{Conflict of Interest}

No potential conflict of interest relevant to this article was reported.

\section{ORCID}

Curie Ahn

https://orcid.org/0000-0001-7033-1102

Samuel Lee

Yeong Hoon Kim

Jieun Oh

Ik Jin Yun

Hyung Joon Ahn

Soo Hyun Seo

Jong Cheol Jeong

Myung Soo Kim

Jongwon $\mathrm{Ha}$

Soon II Kim

In Sung Moon

Won Hyun Cho https://orcid.org/0000-0002-5254-4048

https://orcid.org/0000-0002-4101-9993

https://orcid.org/0000-0001-9429-9602

https://orcid.org/0000-0003-4013-6714

https://orcid.org/0000-0002-7427-0746

https://orcid.org/0000-0002-3866-8650

https://orcid.org/0000-0003-0301-7644

https://orcid.org/0000-0002-8975-8381

https://orcid.org/0000-0003-2285-3517

https://orcid.org/0000-0002-0783-7538

https://orcid.org/0000-0002-5543-6755

https://orcid.org/0000-0001-5916-6601

\section{Author Contributions}

Conceptualization: CRA, WHC, JWH, SIK. Data curation: JCJ, MSL, HJA. Formal analysis: CRA, MSL. Methodology: JEO, IJY, MSL, ISM. Project administration: CRA, SL, SHS. Visualization: CRA. Writing-original draft: CRA, JWH. Writing-review \& editing: CRA, JWH, IJY, SHS.

\section{Additional Contributions}

We would like to acknowledge the Korean Network for Organ Sharing (KONOS), the Korean Organ Agency (KODA), Vitallink and the Korean Society of Transplantation (KST) for their effort in building deceased organ transplantation program in Korea. We would like to thank all the deceased donors and their family members.

\section{REFERENCES}

1. Korean Network for Organ Sharing (KONOS) [Internet]. Seoul: KONOS; 2021 [cited 2021 Sep 20]. Available from: www.konos.go.kr.

2. National Cancer Center. Annual report of cancer statistics in Korea in 2018. Seoul: National Cancer Center; 2018.

3. Korean Network for Organ Sharing (KONOS). 2019 Annual data report [Internet]. Seoul: KONOS; 2020 [cited 2021 Sep 20]. Available from: https://konos.go.kr.

4. International Summit on Transplant Tourism and Organ Trafficking. The Declaration of Istanbul on Organ Trafficking and Transplant Tourism. Clin J Am Soc Nephrol 2008;3:1227-31.

5. The Madrid resolution on organ donation and transplantation: national responsibility in meeting the needs of patients, guided by the WHO principles. Transplantation 2011;91 Suppl 11:S29-31.

6. Ambagtsheer F, de Jong J, Bramer WM, Weimar W. On patients who purchase organ transplants abroad. Am J Transplant 2016;16:2800-15.

7. Park YJ, Kang HJ, Kim EM, Shin WY, Yi NJ, Suh KS, et al. Establishment of active identification and management system for potential brain dead donors in life-link center. J Korean Soc Transplant 2009; 23:43-51.

8. Ahn HJ, Kim HW, Han M, Jeon HJ, Kwon OJ, Ahn C. Changing patterns of foreigner transplants in Korea and overseas organ transplants among Koreans. Transplantation 2018;102:310-7.

9. Global Observatory on Donation and Transplantation (GODT). Executive summary of 2019 activity data [Internet]. Geneva: GODT; 2019 [cited 2021 Sep 20]. Available from: http://www.transplant-observatory.org.

10. Jeon $\mathrm{HJ}$, editor. Causes of donation failure in Korea. Proceedings of the Global Symposium; 2014; Seoul; Seoul National University Hospital.

11. Korea Organ Donation Agency. KODA annual report 2019. Seoul: Korea Organ Donation Agency; 2019.

12. Korean Centers for Decease Control and Prevention (KCDC). Organ donation recognition Survey Report. Cheongju: Korea Disease Control and Prevention Agency; 2018.

13. Lee SM, Lee YH, Kim SH, Kim SY. Study on perceptions and attitudes of Koreans on organ donation. J Korean Soc Transplant 2003;17:227-33.

14. Hur N, Park H, Lee K, Choi G, Kim JM, Park JB, et al. The long-term outcomes of kidney transplantation from donation after circulatory death during brain death donor evaluation in a single center in Korea. $J$ Korean Soc Transplant 2015;29:216-26. 